\title{
Research on Stress Threshold of Deep Buried Coal Rock under Quasi-Static Strain Rate Based on Acoustic Emission
}

\author{
Qijun Hao (D), ${ }^{1,2}$ Xiaohui Liu $\mathbb{D D}^{1,2,3}$ Ankui Hu, ${ }^{1,2}$ Yu Zheng, ${ }^{1,2}$ and Xiaoping Zhao ${ }^{4}$ \\ ${ }^{1}$ Key Laboratory of Fluid and Power Machinery (Xihua University), Ministry of Education, Chengdu 610039, China \\ ${ }^{2}$ School of Energy and Power Engineering, Xihua University, Chengdu 610039, China \\ ${ }^{3}$ Key Laboratory of Deep Earth Science and Engineering (Sichuan University), Ministry of Education, Chengdu 610065, China \\ ${ }^{4}$ Chengdu Hydroelectric Investigation \& Design Institute Corporation, Power China, Chengdu 610072, China \\ Correspondence should be addressed to Xiaohui Liu; liuxh@mail.xhu.edu.cn
}

Received 11 June 2020; Revised 11 August 2020; Accepted 21 August 2020; Published 21 September 2020

Academic Editor: Fengqiang Gong

Copyright (C 2020 Qijun Hao et al. This is an open access article distributed under the Creative Commons Attribution License, which permits unrestricted use, distribution, and reproduction in any medium, provided the original work is properly cited.

\begin{abstract}
The deformation and failure process of coal rock under different strain rates is a significant challenge which must be solved in dynamic excavation. It is important to study the influence of strain rate on the evolution of coal rock crack. The triaxial compression tests and acoustic emission tests under the strain rate of $10^{-5} \mathrm{~s}^{-1}$ to $10^{-3} \mathrm{~s}^{-1}$ were conducted on coal rock using MTS 815 hydraulic servo-control testing machine. During the loading process, acoustic emission energy and spatial distribution have obvious stage characteristics. The damage variable is defined by acoustic emission energy, and the rate of damage evolution is obviously affected by the strain rate. Based on stage characteristics of acoustic emission energy, spatial distribution, and damage evolution, the use of damage evolution curve to determine stress threshold is proposed. In order to verify the rationality of the damage evolution method, the stress threshold values determined by damage evolution method and existing method are compared and analyzed. In order to study the effect of strain rate and confining pressure on the stress threshold, the stress thresholds under uniaxial and triaxial stress states at different strain rates were analyzed.
\end{abstract}

\section{Introduction}

With the development of social economy, the demand for energy has increased in recent years, and the exploitation of mineral resources has gradually emerged as a large-depth feature [1]. Under high geostress environment, the redistribution of stress field caused by excavation will increase the probability of severe disasters such as rock bursts [2]. Therefore, the study of the dynamic mechanical properties of coal under high in situ stress is of great significance to the safety of coal mining.

Acoustic emission (AE) is often accompanied with the instability of coal, so AE technology is widely used in the study of mechanical and deformation characteristics of coal rock [3].Shkuratnik et al. studied AE characteristics of coal rock under uniaxial and triaxial loading $[4,5]$. Liu et al. conducted uniaxial compression tests and $\mathrm{AE}$ tests on different bedding direction of coal rock, indicating that the $\mathrm{AE}$ parameters of vertical bedding coal (including $\mathrm{AE}$ ringdown, $\mathrm{AE}$ energy, and $\mathrm{AE}$ event count rate) were smaller than that of parallel layered coal [6]. Su et al. pointed out that the $\mathrm{AE}$ of coal rock has obvious confining pressure effect, and the AE energy in conventional triaxial test is obviously greater than that in uniaxial test [7]. Considering the dynamic excavation, the effect of strain rate on $\mathrm{AE}$ has attracted much attention. Gao et al. studied the mechanism of the influence of strain rate on the $\mathrm{AE}$ characteristics of rock deformation and found that the $\mathrm{AE}$ rate and the strain rate are highly correlated between the elastic deformation stage and the plastic deformation stage [8]. Li et al. pointed out that the AE peak count increased, and the cumulative count decreased with the strain rate increases [9]. Huang and Liu found that the combination of coal rock decreased the $\mathrm{AE}$ peak count and AE peak energy as the loading rate increased [10]. Wang et al. pointed out that the coal rock failure process and $\mathrm{AE}$ under different strain rates could be divided 
into two periods of periodic linear growth and transient growth [11]. At the same time, the damage variable defined by $\mathrm{AE}$ is used by many scholars to study the mechanical properties of rock. Zhang et al. defined the damage variable by $\mathrm{AE}$ energy and analyzed the difference between different rock mechanical properties [12]. Li and Zhang used cumulative ring-down counts to study damage evolution of coal and rock mass [13]. Cao et al. also defined damage variable using the cumulative ring-down count and pointed out that damage evolution was more sensitive to strain rate and could be divided into three stages [14]. Kim et al. used the stress strain relationship and the AE parameters to define the damage variables, respectively, and pointed out that the damage variables defined by AE parameters were more advantageous in the in situ test [15]. As mentioned above, confining pressure and strain rate have important effects on $\mathrm{AE}$ and mechanical properties of rock, but there are few reports on $\mathrm{AE}$ of coal rock considering strain rate under high confining pressure, so it is significant for the engineering safety to study the mechanical characteristics of high stress coal rock by using AE.

As we all know, the accurate determination of the stress threshold is also particularly important for the design and construction safety of underground engineering, which has attracted a large number of scholars to study it for decades [16-18]. Bieniawski described the failure mechanism of brittle rock and divided the prepeak failure process into four stages corresponding to four stress thresholds, respectively: crack closure stress $\sigma_{\mathrm{cc}}$, crack initiation stress $\sigma_{\mathrm{ci}}$, damage stress $\sigma_{\mathrm{cd}}$, and peak stress $\sigma_{f}$ [19-21]. Among them, crack initiation stress and damage stress are considered as the key parameters for describing the rock mass response of underground caverns $[22,23]$. The method for determining the stress threshold value can be divided into three types: stress strain curve method, AE method [15], and energy dissipation method $[24,25]$. The stress strain method can be subdivided into cumulative crack volume strain method, axial stiffness method, and volume strain method, and many scholars use them to determine the crack initiation stress and damage stress and get good results $[22,26]$. But it is a remarkable fact that there are defects in the stress strain method. For example, in the cumulative crack volume strain method, there are certain human factors in the process of determining elastic modulus and Poisson's ratio [27]. As far as the AE method is concerned, the stress threshold points are determined by using the changing characteristics of AE parameters during compression. Crack initiation and propagation are driven by energy, which is used to determine the stress threshold in the energy dissipation method. Over the years, a large number of studies have used various methods to determine the stress threshold, but there are differences between the results determined by different methods, and the physical meaning behind some methods is not clear. The change law of stress threshold of some rocks (e.g., sandstone, concrete, etc.) under quasi-static strain rate has been studied [28, 29], but considering the discreteness of coal rock, especially, there are few reports on the determination of stress threshold under quasistatic strain rate. Therefore, no matter the determination of the stress threshold of coal rock under quasi-static strain rate, or to have a reliable method to define the stress threshold in laboratory tests, it has important theoretical significance for the safety of coal mines engineering.

Generally speaking, the development and expansion of cracks are the root cause of damage evolution in rocks, and research on damage evolution of rocks is relatively complete $[15,30,31]$, so combining damage mechanics to determine the stress threshold of coal rock is a feasible method. In order to investigate the change of stress threshold of deep buried coal rock under different strain rates, this paper firstly analyzes the results of $\mathrm{AE}$ tests under quasi-static strain rate and uses AE to analyze the damage evolution characteristics of coal rock. Secondly, the stress strain data and AE are used to preliminarily determine the stress threshold of coal rock. Finally, the damage evolution curve is used to determine the stress threshold, and the effects of strain rate and confining pressure on the stress threshold are discussed.

\section{Experiment Test and Damage Theory}

2.1. Coal Sample. The test coal rock is selected from the Furong Baijiao Coal Mine in Yibin City, Sichuan Province, China, with a depth of $450 \mathrm{~m}$. The microscopic characteristics of coal were first analyzed by 5E-MACIII infrared rapid coal quality analyzer. Based on the industrial analysis and the measurement of the calorific value $(20.5 \sim 28.6 \mathrm{MJ} / \mathrm{kg})$, the Furong Baijiao Coal Mine is determined to be sulfur-rich anthracite. Then, X'Pert Pro MPD type diffractometer and XRF-1800 CCED X-ray fluorescence spectrometer were used to quantitatively analyze the internal material composition, element type, and content of coal rock. According to the results obtained by the $\mathrm{X}$-ray diffraction analysis, the main compound of the coal sample was determined to be $\mathrm{SiO}_{2}$ and $\mathrm{AlPO}_{4}$. Finally, combining mineral composition and elemental content measured by X-ray fluorescence analysis, the main components of the coal sample are amorphous minerals $(79.02 \%)$ and quartz $(10.07 \%)$.

In order to possibly reduce the influence of human disturbance on the original state of coal rock, samples are prepared according to the International Society of Rock Mechanics [32]. The coal rock is made into $\varphi 50 \mathrm{~mm} \times L 100 \mathrm{~mm}$ cylindrical sample by the preparation method of coring, cutting, and grinding at both end faces and controlled the diameter of the coal sample at $50_{-2}^{+6} \mathrm{~mm}$ and the ratio of height to diameter at $2 \pm 0.2$. The degree of nonparallelism between the two ends is less than $0.05 \mathrm{~mm}$, the end is perpendicular to the axis of the sample, and the maximum deviation degree is less than $0.25^{\circ}$. The coal rock sample after sample preparation is shown in Figure 1.

2.2. Test Equipment. The coal rock triaxial compression test was carried out on the Sichuan University MTS 815 Flex Test GT rock mechanics test system, with maximum axial load of $4600 \mathrm{kN}$ and maximum confining pressure of $140 \mathrm{MPa}$. During the triaxial loading process, the axial and lateral deformations were measured by the axial extensometer and the circumferential extensometer installed on the surface of the heat shrinkable sleeve and recorded in real time 


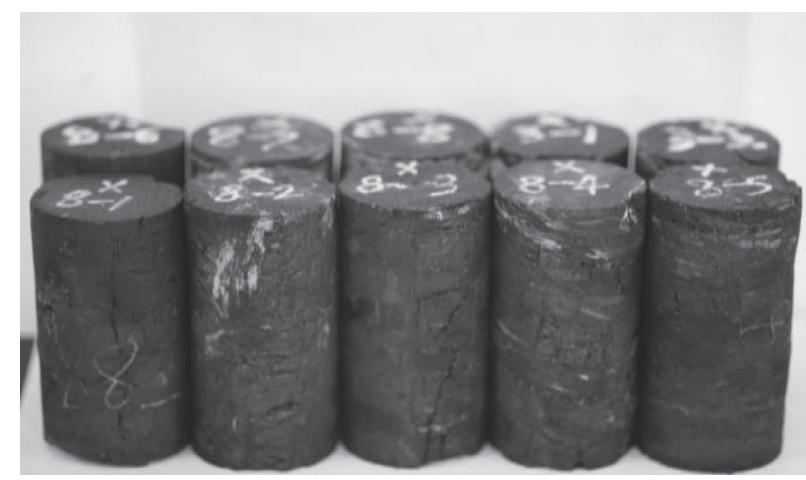

FIGURE 1: Physical map of coal rock.
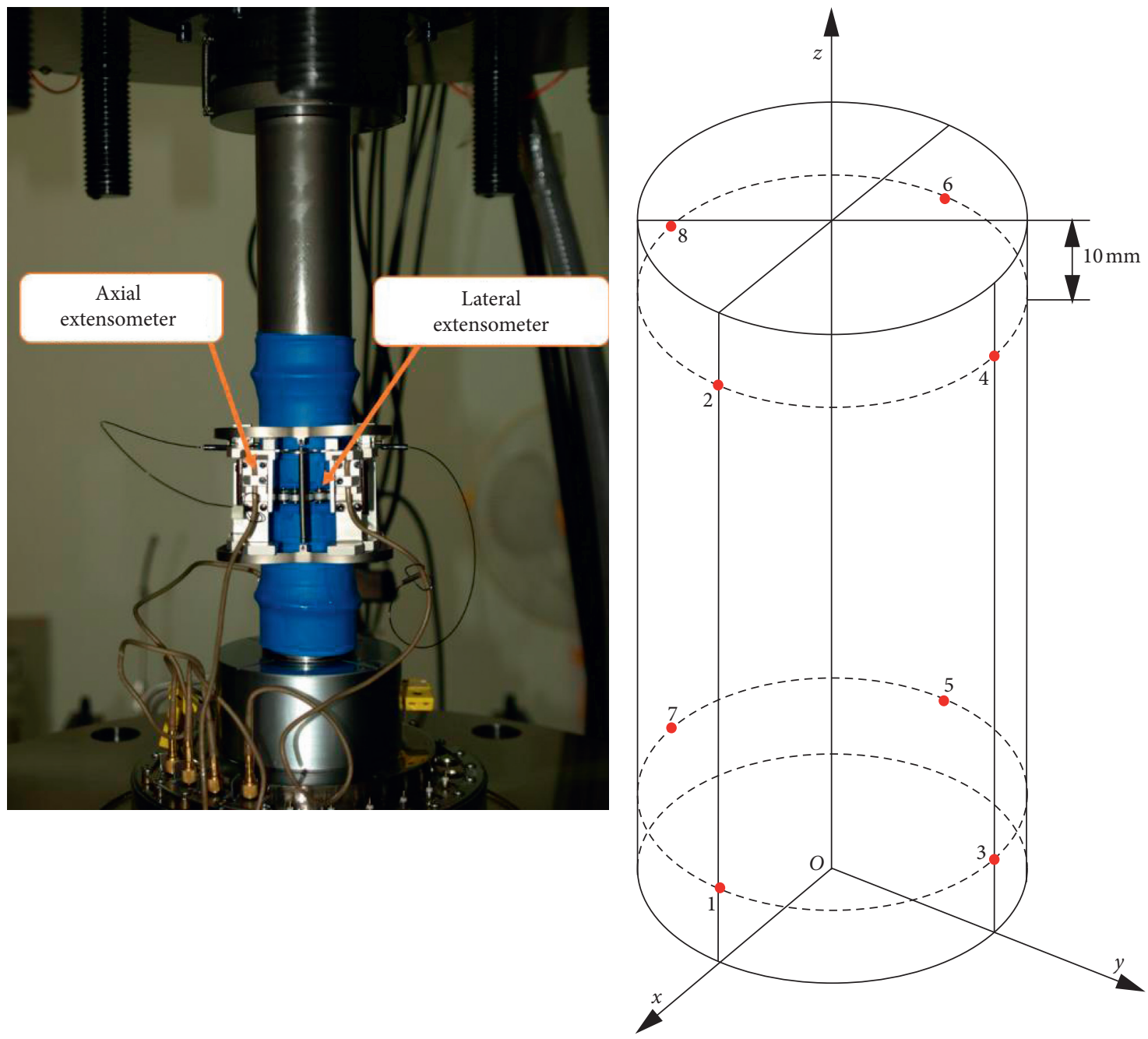

(a)

(b)

Figure 2: Coal rock triaxial compression test system. (a) Triaxial compression test system. (b) Acoustic emission monitoring site.

(Figure 2(a)). Different strain rates are achieved by setting different loading speeds, which are controlled by the linear variable differential transformer (LVDT). To simulate the dynamic disturbance of deep buried coal rock during the normal excavation process, the test loading confining pressure is set to $25 \mathrm{MPa}$ and the loading strain rate is set to $10^{-5} \mathrm{~s}^{-1}, 10^{-4} \mathrm{~s}^{-1}$, and $10^{-3} \mathrm{~s}^{-1}$.

The AE test was performed by the PCI-2 AE test system of the United States. It synchronizes AE feature parameters, waveform acquisition, and analysis. Considering the specific 
conditions of low strength of coal rock and fast attenuation of sound wave, the threshold value of this AE signal acquisition process was set as $40 \mathrm{~dB}$ to minimize the influence of noise in the nonloading process on AE signal. In order to realize real-time monitoring of $\mathrm{AE}$ timing parameters and spatial location, four AE sensors (eight in total) are arranged at the position of $10 \mathrm{~mm}$ above and below the sample in Figure 2(b) (red point) [12].

2.3. Damage Theory Based on AE. The damage variable is defined as [33]

$$
D=\frac{A_{d}}{A}
$$

where $A_{d}$ is the total area of all microcracks on the bearing surface and $A$ is the initial nondestructive section area.

In the existing research, it has been proved that using $\mathrm{AE}$ parameters to define damage variables and perform damage analysis is scientific [15, 34-36]. Therefore, the following damage variables will be established based on $\mathrm{AE}$ parameters.

If $C_{0}$ is defined as the number of $\mathrm{AE}$ counts when the whole section of material is completely destroyed, the number of $\mathrm{AE}$ events per unit area of the coal rock microelements at the time of failure $C_{w}$ is

$$
C_{w}=\frac{C_{0}}{A}
$$

When the area of the damage of the section is $A_{d}$, the number of $\mathrm{AE}$ events is

$$
C_{d}=C_{w} A_{d}=\frac{C_{0}}{A} A_{d}
$$

So, the damage variable can be defined as

$$
D=\frac{C_{d}}{C_{0}} \text {. }
$$

Due to the confining pressure limitation, the coal rock after the peak strength still has bearing capacity, and the samples have not reached a fully damaged state $[13,14]$. Therefore, a correction coefficient $D_{u}$ is introduced to correct $D$, and its physical meaning can be expressed as

$$
D_{u}=1-\frac{\sigma_{r}}{\sigma_{f}}
$$

where $\sigma_{r}$ is the residual strength of coal rock and $\sigma_{f}$ is the peak strength of coal rock.

So, the damage variable can be revised as

$$
D=D_{u} \frac{C_{d}}{C_{0}}=\left(1-\frac{\sigma_{r}}{\sigma_{f}}\right) \frac{C_{d}}{C_{0}} .
$$

\section{Test Results and Analysis}

3.1. Evolution Characteristics of AE Energy. According to the $\mathrm{AE}$ and MTS tests, Figure 3 is the curve of the evolution of AE energy and stress with time under different strain rates.
The AE energy curve at different strain rates can be divided into four stages according to its evolution characteristics: (i) quiet stage, (ii) stable growth stage, (iii) fast growth stage, and (iv) postpeak stage. (i) In quiet stage, the rock is under small load, and defects such as primary cracks and holes in the coal rock are compacted under the action of axial pressure. However, since the energy of AE signal produced by crack closure is low [37], it is not easy to be captured by the AE sensor, so no AE signal is produced at this stage, and the AE energy is 0 . (ii) In stable growth stage, the material is in the elastic stage, and the stress of coal rock and AE energy keep linear relationship with time. Since the axial pressure has not increased to the stress condition that produces a large amount of $\mathrm{AE}$, the $\mathrm{AE}$ signal is produced in small amount, and the AE energy curve grows slowly. (iii) In fast growth stage, as the stress increases, the coal rock gradually yields, a large number of cracks are produced, and the AE enters a stage of rapid growth. Compared with the second stage, the AE energy growth rate is faster; that is, the average slope of the curve increases significantly. (iv) In postpeak stage, the load of coal gradually exceeds its ultimate strength, and macroscopic cracks begin to form. The occurrence of a large number of cracks and the friction of the macroscopic crack surface lead to a rapid increase in the AE energy, and at the same time the increase rate is greater than that in the third stage.

At the same time, it can be seen from Figure 3 that as the strain rate increases, there are differences in the evolution of AE energy. Firstly, the AE energy corresponding to the peak stress decreases gradually as the strain rate increases from $10^{-5} \mathrm{~s}^{-1}$ to $10^{-3} \mathrm{~s}^{-1}$, and the average AE energy of three groups of coal samples decreases from 4.055 to 1.813 $\left(9.31 \times 10^{-19} \mathrm{~J}\right)$. This is because, at faster loading rates, cracks with smaller discharge energy and smaller dimensions are more activated. Meanwhile, the loss of AE signal increases with the increase of crack number. The two factors cause the AE energy to be smaller at higher strain rate. Then, with the increase of strain rate, the evolution rate of AE energy at each stage is obviously accelerated because of the acceleration of test rate. In Figures 3(a) to 3(c), for example, the rate of energy evolution in the second stage increases from 0.827 to $34.182\left(9.31 \times 10^{-22} \mathrm{~J} / \mathrm{s}\right)$. From the perspective of the $\mathrm{AE}$ energy curve as a whole, the increase in strain rate leads to more obvious phase characteristics of the curve. For example, the turning point of the stable growth stage and fast growth stage stages of Figure 3(c) is easier to identify compared to that of Figure 3(a).

3.2. AE Spatial Distribution Characteristics. In order to further explore the evolution law of AE in coal under quasistatic strain rates, the AE spatial distribution diagram of each stress level section of a typical coal sample in each strain rate is selected as shown in Figure 4.

The AE spatial distribution under different strain rates shows that when the stress level is less than $50 \%$, the energy is mainly stored in coal and rock by elastic energy, and the amount of AE is small in this period. As the stress continues to increase near the peak stress, the concentration of $\mathrm{AE}$ 


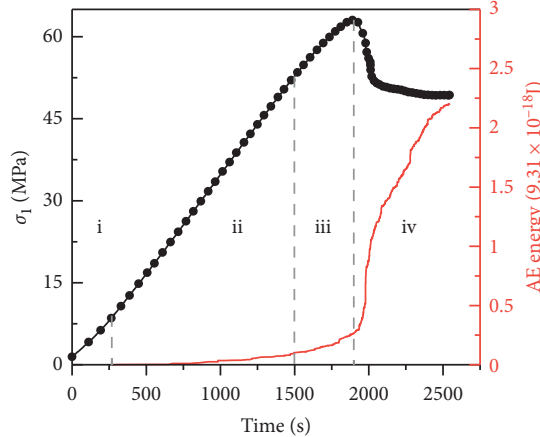

$\rightarrow \sigma_{1}$

- AE energy

$\left(a_{1}\right)$ 5-1

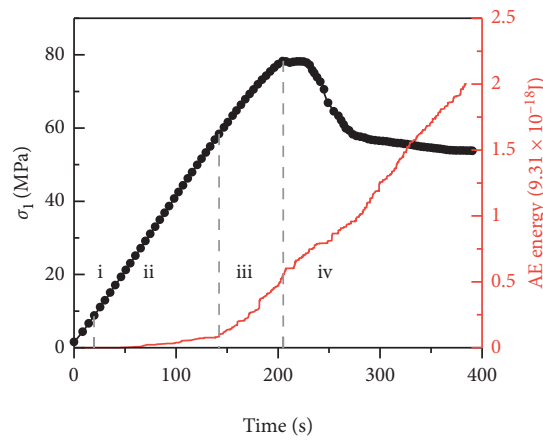

$\rightarrow \sigma_{1}$

$\longrightarrow$ AE energy

$\left(b_{1}\right) 4-1$

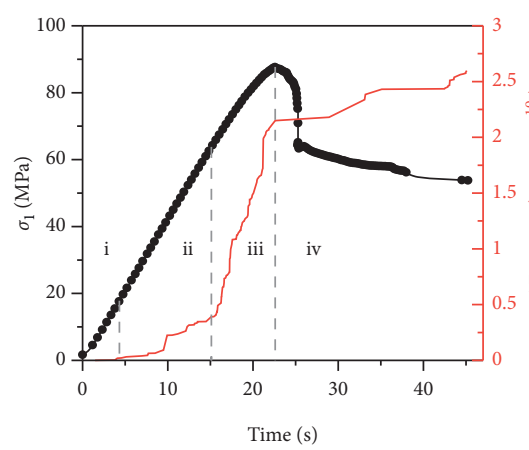

$\rightarrow \sigma_{1}$

- AE energy

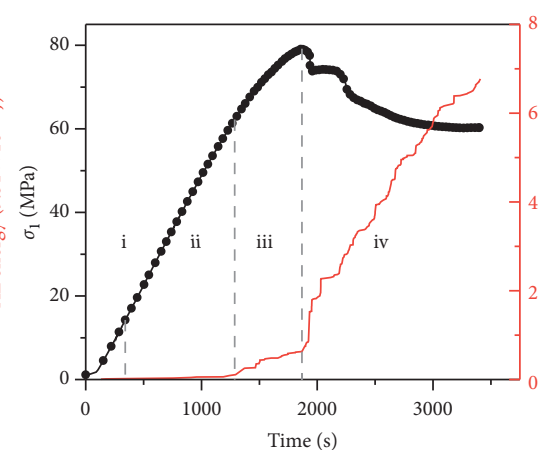

$\rightarrow \sigma_{1}$

- AE energy

$\left(a_{2}\right)$ 5-2

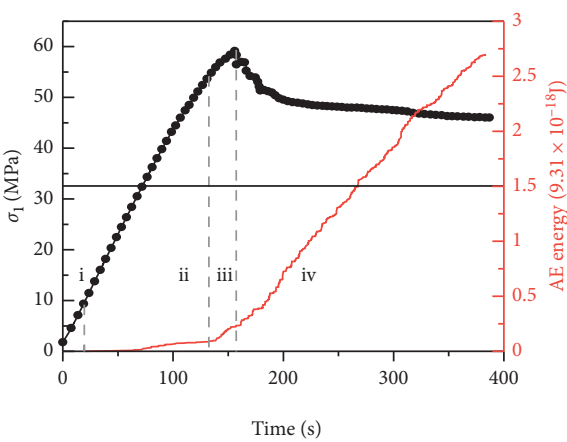

$\rightarrow \sigma_{1}$

AE energy

$\left(b_{2}\right) 4-2$

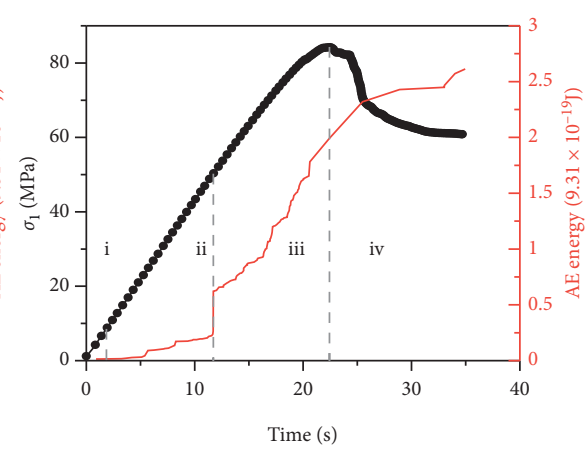

$\longrightarrow \sigma_{1}$
$-\mathrm{AE}$ energy

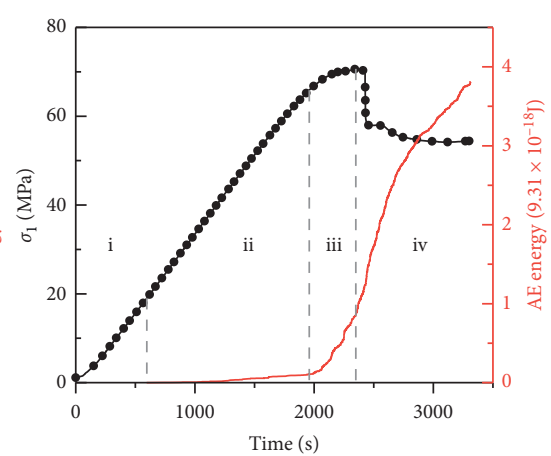

$\rightarrow \sigma_{1}$

$\left(a_{3}\right) 5-3$

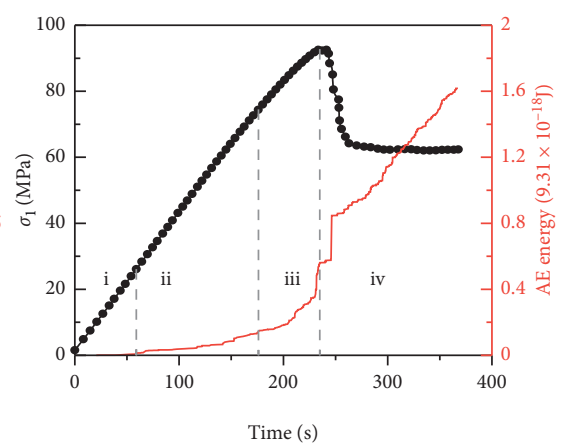

$\rightarrow \sigma_{1}$

— AE energy

(b $)$ 4-3

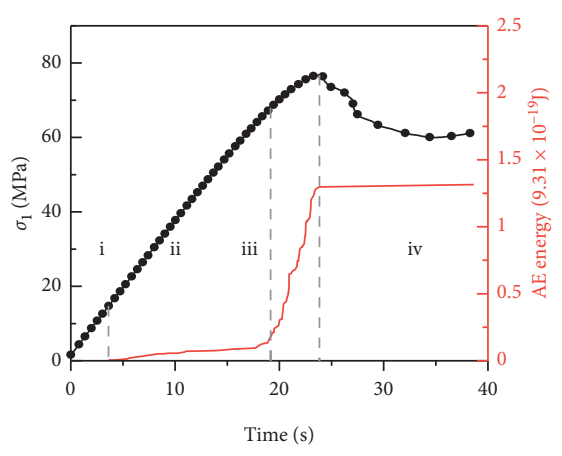

$\rightarrow \sigma_{1}$

$\left(c_{1}\right) 3-1 \quad\left(c_{2}\right) 3-2$

FIgURe 3: AE energy at different strain rates. (a) $\dot{\varepsilon}=10^{-5} \mathrm{~s}^{-1}$. (b $\dot{\varepsilon}=10^{-4} \mathrm{~s}^{-1}$. (c) $\dot{\varepsilon}=10^{-3} \mathrm{~s}^{-1}$.

signals indicates that the cracks in a certain region begin to connect with each other and propagate. This corresponds to the rapid increase in the AE energy of the third stage in Figure 3. From Figure 4, we can summarize the three laws of AE evolution with strain rate: (1) With the increase of strain rate, the concentration of $\mathrm{AE}$ in the coal rock space decreases obviously. When the strain rate is $10^{-5} \mathrm{~s}^{-1}$, AE is concentrated at $90-100 \%$ stress level with obvious nucleation area. When the strain rates are $10^{-4} \mathrm{~s}^{-1}$ and $10^{-3} \mathrm{~s}^{-1}$, the $\mathrm{AE}$ distribution becomes more uniform and dispersed in the space. (2) The stress level, which mainly produces AE signal, decreases with the increase of strain rate. When the strain rate is $10^{-5} \mathrm{~s}^{-1}$, the stress level of a large number of $\mathrm{AE}$ signals is mainly from $90 \%$ before the peak to $80 \%$ after the peak. When the strain rate is $10^{-4} \mathrm{~s}^{-1}$, it is $80 \%$ before peak to $90 \%$ after peak, and when the strain rate is $10^{-3} \mathrm{~s}^{-1}$, it is $70 \%$ before peak to peak stress. (3) As can be seen clearly from Figure 4, the amount of AE decreases with the increase of strain rate. It means that it is more difficult to predict rock failure by AE monitoring with the speed of excavation.

3.3. Damage Performance Based on AE Energy. In view of the fact that the AE energy curve and the spatial distribution of 


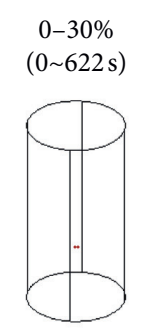

70-80\%

(1453 1655s)

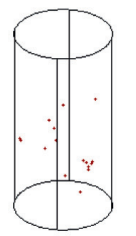

$0-10 \%$

(0 19s)

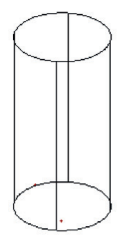

60-70\%

(115 135s)

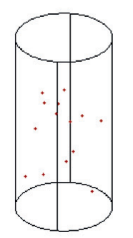

$0-10 \%$

(0 2s)

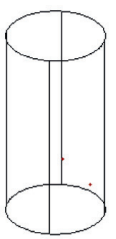

60-70\%

(12 14s)

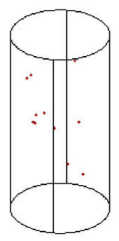

30-40\%

(622 886s)

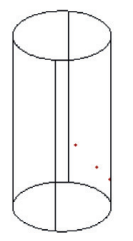

80-90\%

(1655 1877s)

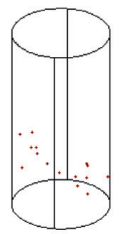

$10-20 \%$

(19 46s)

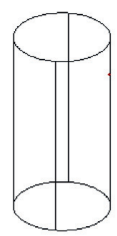

70-80\%

(135 153s)

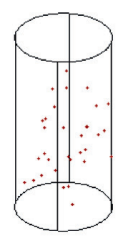

10-20\%

(2 4s)

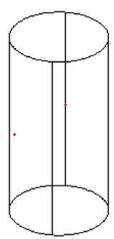

70-80\%

(14 16s)

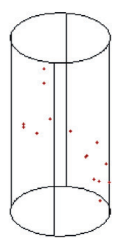

40-50\%

(886 1059s)

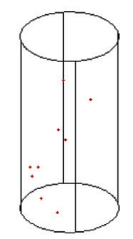

90-100\%

(1877 2316s)

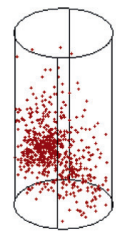

(a)

20-30\%

(46 58s)

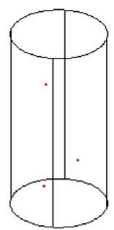

80-90\%

(153 176s)

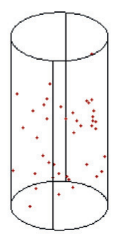

20-30\%

(4 6s)

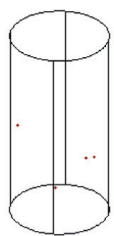

80-90\%

(16 19s)

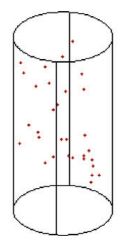

(b)
50-60\%

(1059 1267s)

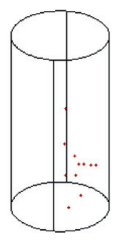

100-90\%

(2316 2395s)

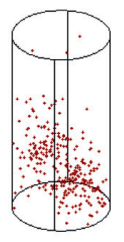

40-50\%

(80 96s)

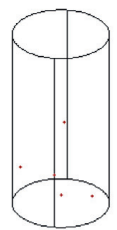

100-90\%

(205 248s)

(175 205s)

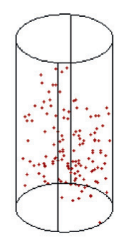

30-40\%

(6 8s)

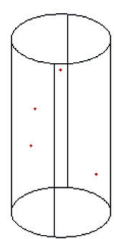

90-100\%

(19 22s)

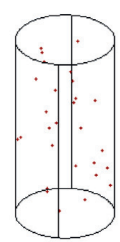

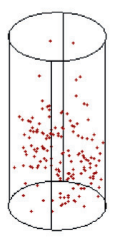

40-50\%

(9 10s)

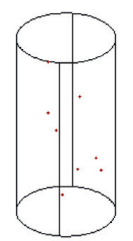

100-90\%

(22 25s)

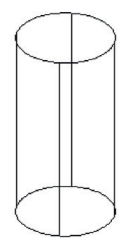

60-70\%

(1267 1453s)

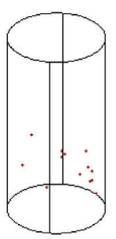

90-80\%

(2395 2639s)

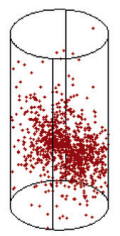

50-60\%

(96 115s)

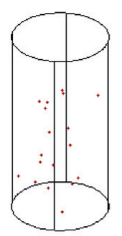

90-80\%

(248 261s)

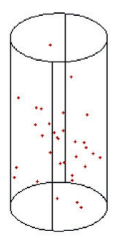

50-60\%

(10 12s)

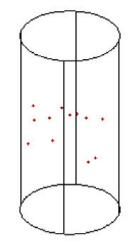

90-80\%

(25 29s)

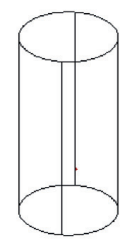

(c)

Figure 4: AE spatial distribution at different strain rates. (a) $\dot{\varepsilon}=10^{-5} \mathrm{~s}^{-1}$. (b) $\dot{\varepsilon}=10^{-4} \mathrm{~s}^{-1}$. (c) $\dot{\varepsilon}=10^{-3} \mathrm{~s}^{-1}$.

coal rock are analyzed from the surface, the analysis of damage evolution from the damage theory is closer to the essence of the mechanical properties. Therefore, in combination with equation (6), the AE energy at the end of the test is used to determine $C_{0}$, and the evolution curve of the damage variable with the stress level is calculated as shown in Figure 5. 


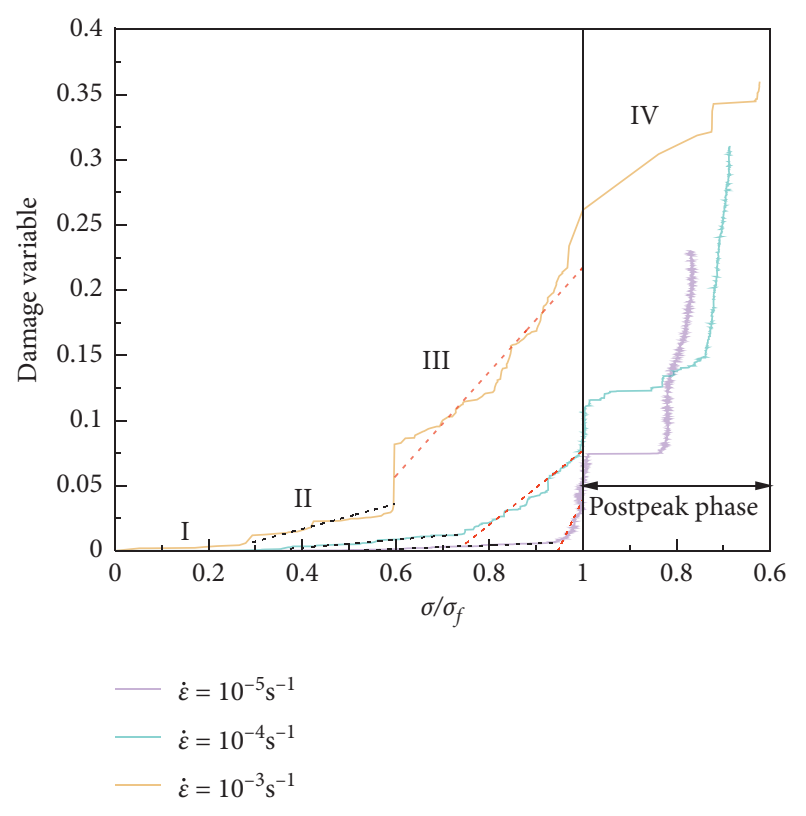

Figure 5: Damage evolution under different strain rates.

As shown in Figure 5, the damage evolution curves of coal rock under different strain rates also have four stages similar to AE energy: (I) initial calm, (II) stable damage evolution, (III) rapid damage evolution, and (IV) postpeak stage. In the initial calm stage, no new cracks are generated, so the number of $\mathrm{AE}$ is small, and the damage variable is zero. With the increase of stress level, the new crack increases in order, and the damage evolution shows a linear increasing trend at the second stage. In the rapid damage evolution stage, the crack increases rapidly with the increase of stress, so the number of AE increases greatly, and the damage evolution curve presents obvious nonlinear growth trend. Meanwhile, as the strain rate increases, the $\left(\sigma / \sigma_{f}\right)$ value at the end of the initial calm and stable damage evolution phase decreases. Specifically, as the strain rate increases from $10^{-5} \mathrm{~s}^{-1}$ to $10^{-3} \mathrm{~s}^{-1}$, the $\left(\sigma / \sigma_{f}\right)$ value at the end of the initial quiet period decreases from 0.538 to 0.350 , and the $\left(\sigma / \sigma_{f}\right)$ value at the end of the stable damage evolution phase decreases from 0.924 to 0.804 . It can be clearly seen that as the strain rate increases, the rate of change in the stage of stable damage evolution increases, and the rate of change in the stage of rapid damage evolution decreases. This is because the strain energy in the early stage of coal rock is more saved at low strain rate, and near the peak stress crack propagation leads to a large amount of strain energy release, resulting in greater damage evolution rate.

\section{Determination of Stress Threshold}

4.1. Determination of Stress Threshold Based on Damage Evolution. Based on the above, it is very clear that there are several stages, whether the change of AE energy, AE spatial distribution, or damage curves. In other words, under the quasi-static strain rate, the changes in the mechanical properties of coal rock have obvious stages, and those stages can be expressed by the stress threshold in actual engineering practice.
The most common method to determine the stress threshold is the crack volumetric strain method. Many researchers have discussed the crack volumetric strain of rocks using formulas $\varepsilon_{V \text { crack }}=\varepsilon_{v}-(1 / E)\left(\sigma_{1}-2 \mu \sigma_{3}\right)$ and pointed out that when the stress reaches $\sigma_{\mathrm{cc}}$ and $\sigma_{\mathrm{ci}}$, the crack volumetric strain will be zero $[16,38,39]$. The damage stress $\sigma_{c d}$ is usually determined by the inflection point of the volumetric strain, that is, the expansion point of the rock. However, it can be seen from Figure 6(a) that, under different strain rates, the crack volume strain before the peak stress point is greater than 0 . So, for coal rock, the crack initiation stress $\sigma_{\mathrm{ci}}$ cannot be determined by the crack volumetric strain method, due to the nonlinear nature of coal rock. As Figure 6(b) shows, when $\dot{\varepsilon}=10^{-5} \mathrm{~s}^{-1}$ or $\dot{\varepsilon}=10^{-4} \mathrm{~s}^{-1}$, the strength limit of coal rock is reached, but the volumetric strain has not yet reached the maximum value, so the volume strain method cannot be used to determine the damage stress $\sigma_{c d}$ at this time. When the strain rate is $10^{-3} \mathrm{~s}^{-1}$, the maximum volume strain appears before the peak stress point, so the damage stress $\sigma_{\text {cd }}$ can be determined in this case. Therefore, the location where the maximum volume strain appears is not fixed in Figure 6(b), which makes it difficult to determine the damage stress $\sigma_{\text {cd }}$ only by the volume strain method.

As mentioned above, it is difficult to determine the characteristic stress values by a traditional method. Meanwhile, in view of the obvious stage characteristics of the damage evolution curves of coal rock under different strain rates in Section 3.3, the initiation stress $\sigma_{\mathrm{ci}}$ and damage stress $\sigma_{\mathrm{cd}}$ are determined by the damage evolution curve in the following. Figure 7 shows the damage evolution law of three coal rock samples at the strain rate of $10^{-3} \mathrm{~s}^{-1}$, indicating that coal-rock damage at the same strain rate also has periodic characteristics. Before the stable damage evolution stage, coal rock is in the initial damage quiet period, and coal rock undergoes the crack compaction stage and the linear elastic stage. In those processes, the damage of the coal rock is caused only by the compaction of the crack, so the damage variable value is close to 0 . When entering the stage of damage stable evolution stage, coal-rock deformation is mainly elastic deformation, a small amount of AE signals is generated, and internal fractures of coal rock started to form. So, the initiation stress $\sigma_{\mathrm{ci}}$ can be identified as the start of initial calm period. As damage evolution continues, the damage rate accelerates significantly, and a large number of AE signals are generated; therefore, the junction of the stable and rapid damage evolution stages can be considered as the beginning of the unstable crack growth, that is, the damage stress point $\sigma_{\text {cd }}$.

4.2. Stress Threshold at Different Strain Rates. The stress thresholds determined by the damage evolution method (DE method) are listed in Table 1 in order to clarify the variation of the response stress threshold with strain rate.

With the increase of strain rate, the average damage stress $\overline{\sigma_{\mathrm{cd}}}$ (or the average initiation stress $\overline{\sigma_{\mathrm{ci}}}$ ) changes from 60.072 to 60.601 (or from 38.655 to 29.770), and the change amplitude is small. It is also worth noting that as 


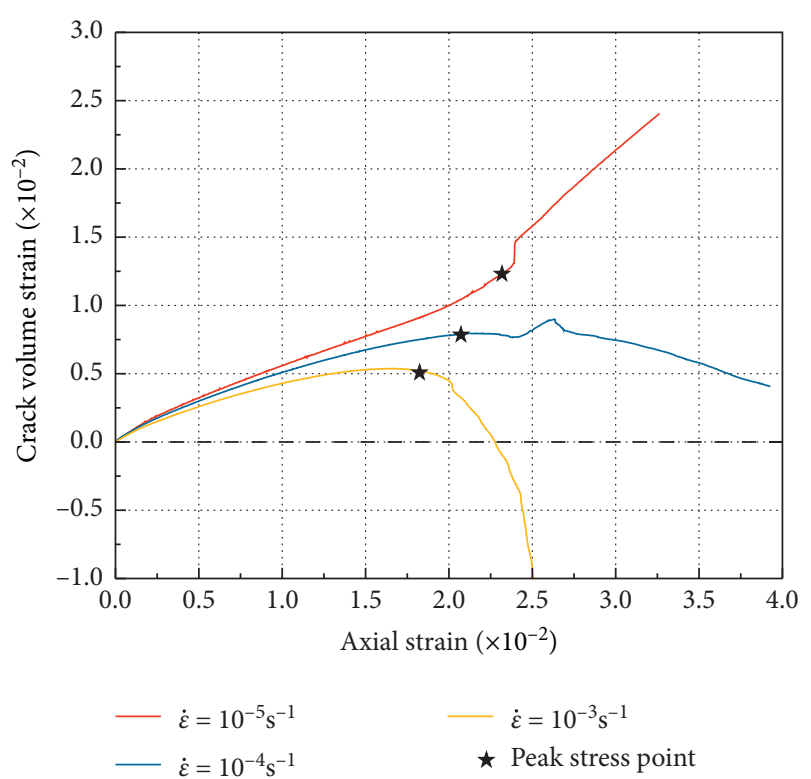

(a)

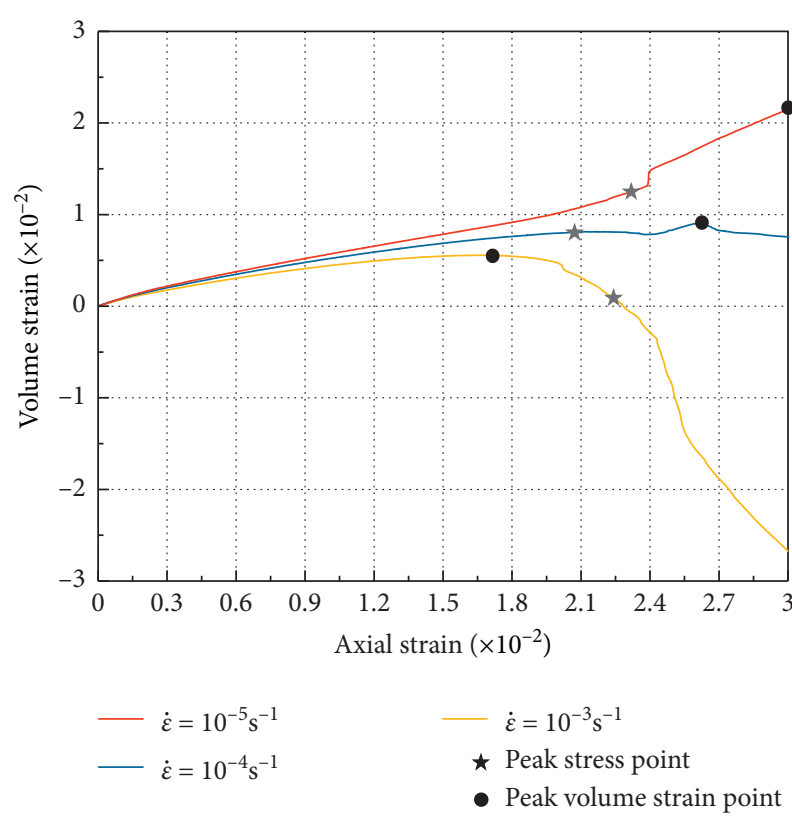

(b)

FIGURE 6: Different methods to determine stress threshold: (a) crack volumetric strain method; (b) volume strain method.

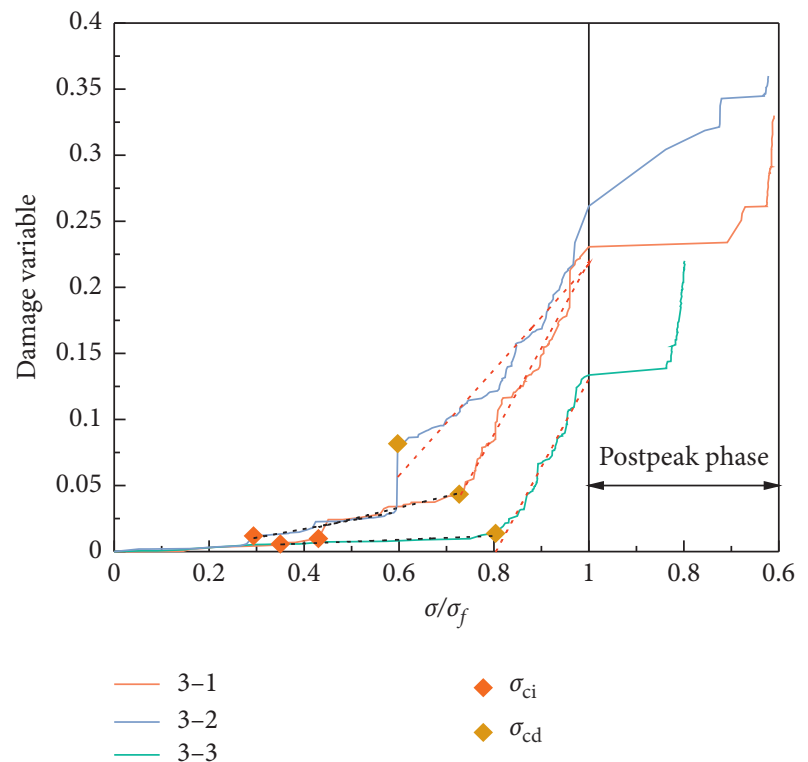

FIgURE 7: Stress threshold and the damage evolution curve in $10^{-3} \mathrm{~s}^{-1}$.

the peak stress increases from [63.090, 79.217] to [76.847, $87.702]$, the ratio (e.g., $\left.\left(\sigma_{\mathrm{ci}} / \sigma_{f}\right)\right)$ decreases from $[0.539$, $0.551]$ to $[0.293,0.430]$ as the strain rate increases, showing a clear decreasing trend. As the stress rate increases from $10^{-5} \mathrm{~s}^{-1}$ to $10^{-3} \mathrm{~s}^{-1}$, the average value of $\left(\sigma_{\mathrm{ci}} / \sigma_{f}\right)$ decreases from 0.544 to 0.358 , and the average value of $\left(\sigma_{\mathrm{cd}} / \sigma_{f}\right)$ decreases from 0.848 to 0.709 . Some scholars have found the same law through research, pointing out that the internal damage of rocks is more likely to form under high strain rate conditions, which leads to a reduction in $\overline{\left(\sigma_{\mathrm{ci}} / \sigma_{f}\right)}$ and $\overline{\left(\sigma_{\mathrm{cd}} / \sigma_{f}\right)}[29,40]$. We should note that the strain rate has a significant effect on the development of cracks, both from the existing studies and from the fracture morphology of coal rock in Figure 8 $[41,42]$. As the strain rate increases from $10^{-5} \mathrm{~s}^{-1}$ to $10^{-3} \mathrm{~s}^{-1}$, the degree of coal-rock fragmentation increases, and the proportion of low-size broken coal blocks becomes greater. Microdefects (e.g., microcracks and microvoids) with higher strain rate are easier to activate under lower stress [42]. Therefore, it is easier to satisfy the crack initiation conditions at the defects and to propagate and penetrate for cracks. As a result, $\overline{\left(\sigma_{\mathrm{ci}} / \sigma_{f}\right)}$ and $\overline{\left(\sigma_{\mathrm{cd}} / \sigma_{f}\right)}$ gradually decrease with increasing strain rate.

4.3. Determination of Stress Threshold by Existing Method. In order to discuss the rationality of using the DE method to determine the stress threshold and compare with the existing method, the following will first introduce the feasible existing method and determine the stress threshold.

As described in section 4.1, when the strain rate is $10^{-3} \mathrm{~s}^{-1}$, the damage stress $\sigma_{\mathrm{cd}}$ can be determined by the volume strain method but not by the method completely, so it must be determined in combination with acoustic emission. As shown in Figure 9, when the stress reaches the damage stress $\sigma_{c d}$, the AE energy rate will have obvious protrusions after the quiet period, because the expansion of the crack leads to a sudden increase in the number of $\mathrm{AE}$ signals.

Based on the determination of damage stress $\sigma_{\mathrm{cd}}$, Nicksiar and Martin proposed a method for accurately determining the initiation stress $\sigma_{c i}$ through the lateral strain curve-lateral strain response ( $\triangle \mathrm{LSR}$ ) method [26]. First, determine the reference line by connecting the damage stress point and the stress zero point, and calculate 
TABLE 1: Stress characteristic values with different strain rates.

\begin{tabular}{|c|c|c|c|c|c|c|c|c|c|c|}
\hline$\dot{\varepsilon}$ & Group & $\left(\sigma_{\mathrm{ci}} / \mathrm{MPa}\right)$ & $\overline{\sigma_{\mathrm{ci}}}$ & $\left(\sigma_{\mathrm{ci}} / \sigma_{f}\right)$ & $\overline{\left(\sigma_{\mathrm{ci}} / \sigma_{f}\right)}$ & $\left(\sigma_{\mathrm{cd}} / \mathrm{MPa}\right)$ & $\overline{\sigma_{\mathrm{cd}}}$ & $\left(\sigma_{\mathrm{cd}} / \sigma_{f}\right)$ & $\overline{\left(\sigma_{\mathrm{cd}} / \sigma_{f}\right)}$ & $\left(\sigma_{f} / \mathrm{MPa}\right)$ \\
\hline \multirow{3}{*}{$10^{-5}$} & $5-1$ & 34.195 & \multirow{3}{*}{38.655} & 0.542 & & 52.680 & \multirow{3}{*}{60.072} & 0.835 & \multirow{3}{*}{0.848} & 63.090 \\
\hline & $5-2$ & 43.649 & & 0.551 & 0.544 & 62.185 & & 0.785 & & 79.217 \\
\hline & $5-3$ & 38.121 & & 0.539 & & 65.350 & & 0.924 & & 70.725 \\
\hline \multirow{3}{*}{$10^{-4}$} & $4-1$ & 29.772 & \multirow{3}{*}{38.680} & 0.380 & & 58.448 & \multirow{3}{*}{62.340} & 0.746 & \multirow{3}{*}{0.820} & 78.348 \\
\hline & $4-2$ & 35.637 & & 0.600 & 0.509 & 54.109 & & 0.911 & & 59.395 \\
\hline & 4-3 & 50.632 & & 0.546 & & 74.465 & & 0.803 & & 92.733 \\
\hline \multirow{3}{*}{$10^{-3}$} & $3-1$ & 37.712 & \multirow{3}{*}{29.770} & 0.430 & & 63.759 & \multirow{3}{*}{60.601} & 0.727 & \multirow{3}{*}{0.735} & 87.702 \\
\hline & $3-2$ & 24.701 & & 0.293 & 0.358 & 50.264 & & 0.596 & & 84.305 \\
\hline & $3-3$ & 26.896 & & 0.350 & & 67.781 & & 0.882 & & 76.847 \\
\hline
\end{tabular}

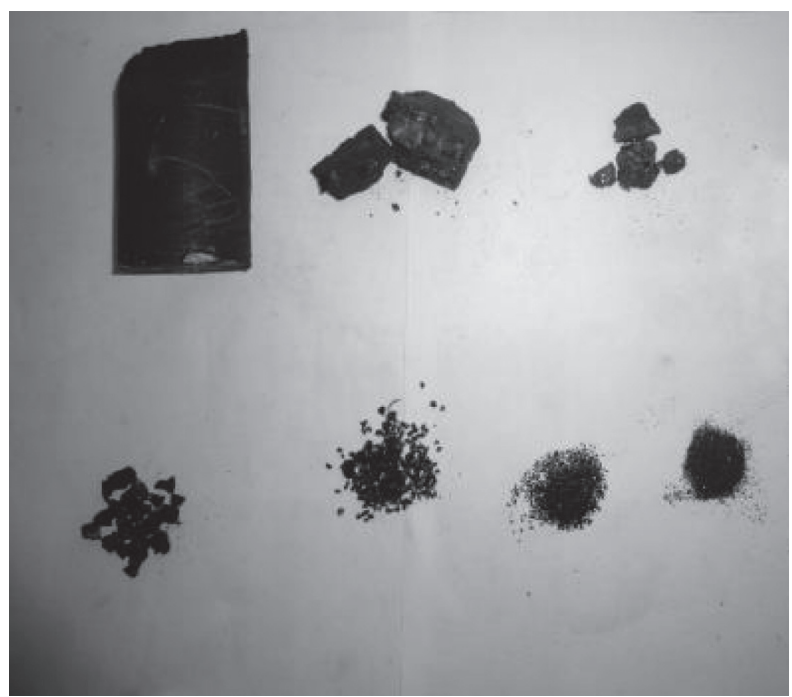

(a)

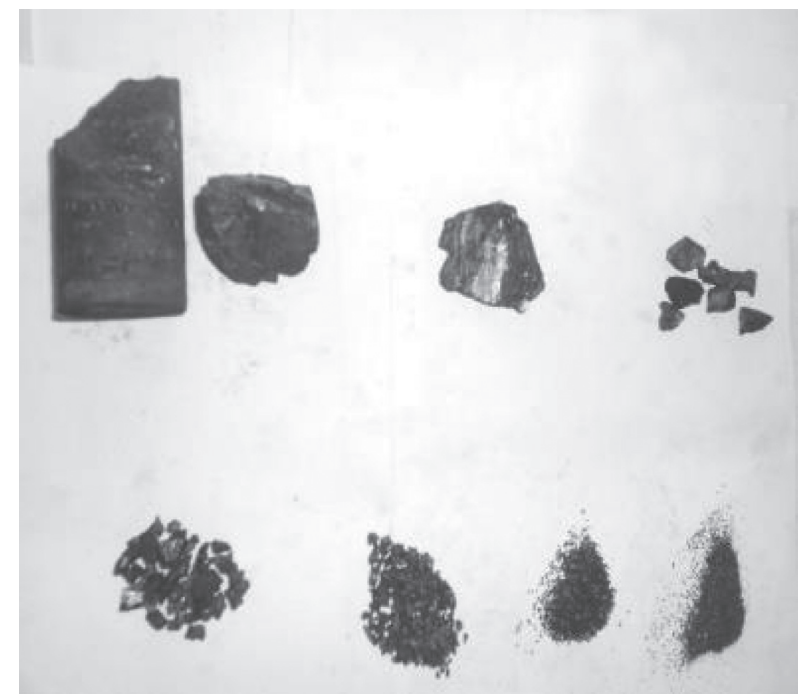

(b)

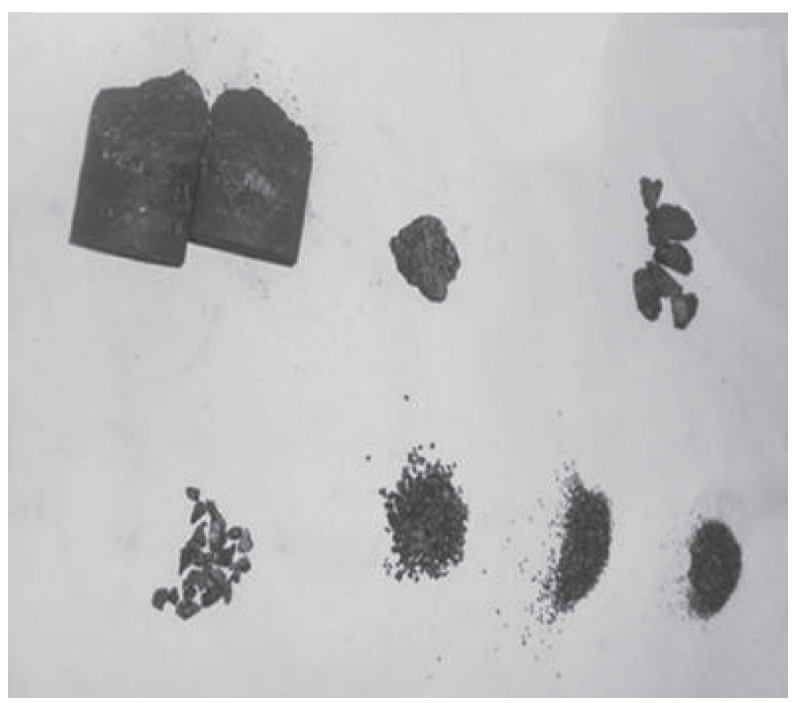

(c)

Figure 8: Failure patterns of coal rock under different strain rates. (a) $\dot{\varepsilon}=10^{-5} \mathrm{~s}^{-1}$. (b) $\dot{\varepsilon}=10^{-4} \mathrm{~s}^{-1}$. (c) $\dot{\varepsilon}=10^{-3} \mathrm{~s}^{-1}$.

the difference between the lateral strain and the reference line under the same stress in Figure 10(a), the lateral strain difference $(\triangle \mathrm{LSR})$. Then, as shown in Figure $10(\mathrm{~b})$, determine the stress point corresponding to the maximum lateral strain difference as the initiation stress point $\sigma_{\mathrm{ci}}$. $\left(\sigma_{\mathrm{ci}} / \sigma_{f}\right)$ and $\left(\sigma_{\mathrm{cd}} / \sigma_{f}\right)$ determined by the two methods at different strain rates are shown in Figure 11. First, $\left(\sigma_{\mathrm{ci}} / \sigma_{f}\right)$ is determined by the existing method; with the strain rate increasing from $10^{-5}$ to $10^{-3} \mathrm{~s}^{-1}$, the average value changed from 0.409 to 0.415 , and the average value 


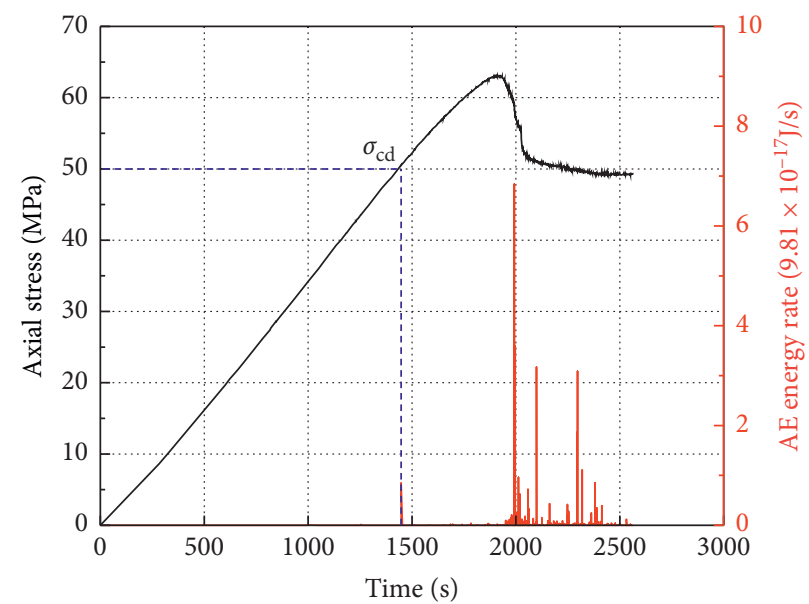

Figure 9: Determination of damage stress point of coal rock by AE method $\left(\dot{\varepsilon}=10^{-5} \mathrm{~s}^{-1}\right)$.

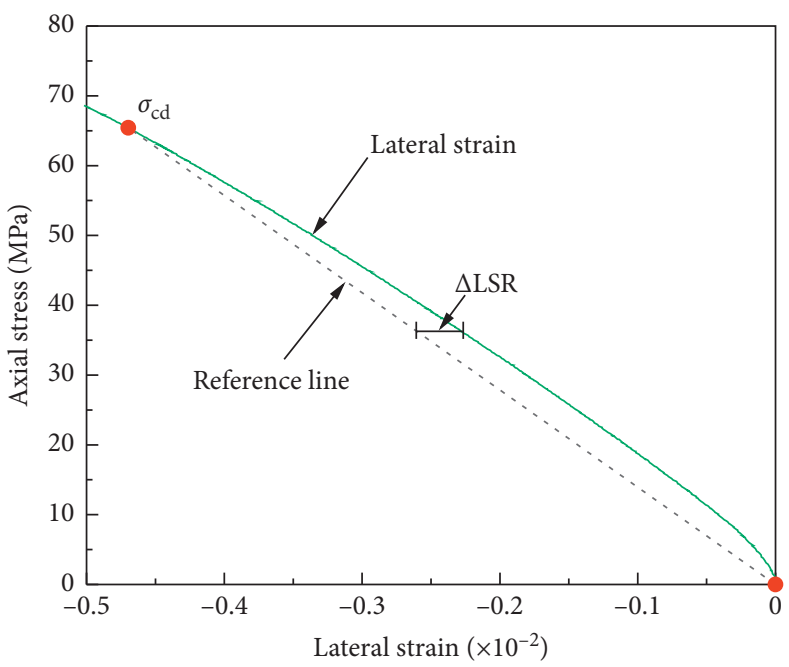

(a)

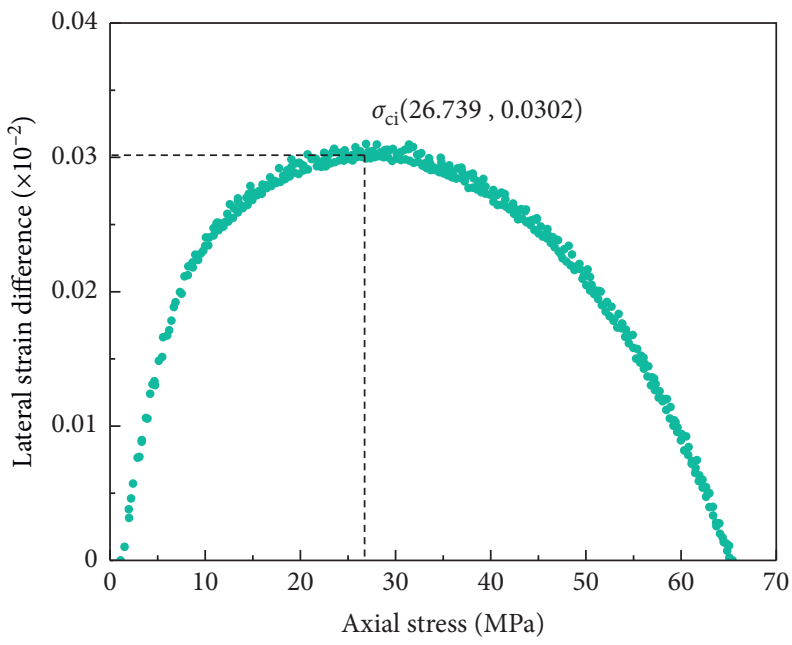

(b)

FiguRE 10: Determination of initiation stress using lateral strain response method. (a) Lateral strain difference of coal rock. (b) Determination of initiation stress.

of $\left(\sigma_{\mathrm{cd}} / \sigma_{f}\right)$ decreased from 0.867 to 0.806 . Comparing $\left(\sigma_{\mathrm{ci}} / \sigma_{f}\right)$ and $\left(\sigma_{\mathrm{cd}} / \sigma_{f}\right)$ determined by the two methods, they all show a certain tendency to decline, which shows that the DE method is effective to determine the stress threshold value. At the same time, as the strain rate increases, $\left(\sigma_{\mathrm{ci}} / \sigma_{f}\right)$ and $\left(\sigma_{\mathrm{cd}} / \sigma_{f}\right)$ determined by DE method show a more obvious decreasing trend. For deep geotechnical engineering, an increase in the excavation rate or an increase in the surrounding rock strain rate will often increase the probability of engineering disasters such as collapse and rock burst. Thus, smaller stress threshold, determined by DE method, has more safety guarantees for engineering excavation.

4.4. Comparison of Stress Thresholds under Uniaxial and Triaxial Conditions. The ratio of stress threshold to peak stress in uniaxial and triaxial state is listed in Table 2 to analyze the effect of confining pressure on stress threshold at different strain rates. The stress threshold in uniaxial state is determined by energy dissipation rate method and $\triangle$ LSR method in the paper in [43]. In the uniaxial stress state, $\overline{\left(\sigma_{\mathrm{ci}} / \sigma_{f}\right)}$ (or $\left.\overline{\left(\sigma_{\mathrm{cd}} / \sigma_{f}\right)}\right)$ decreases with the increase of the strain rate, from 0.627 to 0.536 (or from 0.883 to 0.828 ), showing the same law as that in the triaxial state. Under the same strain rate, $\overline{\left(\sigma_{\mathrm{ci}} / \sigma_{f}\right)}$ and $\overline{\left(\sigma_{\mathrm{cd}} / \sigma_{f}\right)}$ in uniaxial state are greater than those in triaxial state. At the same time, with the increase of strain rate, the difference of $\overline{\left(\sigma_{\mathrm{ci}} / \sigma_{f}\right)}$ (or $\left.\overline{\left(\sigma_{\mathrm{cd}} / \sigma_{f}\right)}\right)$ between uniaxial and triaxial states will increase. For example, for $\overline{\left(\sigma_{\mathrm{ci}} / \sigma_{f}\right)}$, when the strain rate is $10^{-5} \mathrm{~s}^{-1}$, the difference is 0.083 , and when the strain rate is $10^{-3} \mathrm{~s}^{-1}$, the difference increases to 0.178 . This means that the stress state of the original rock and the excavation rate have a positive effect on the evolution of cracks. In the triaxial stress state, the rock absorbs more energy when reaching the same stress level compared to the uniaxial stress, the 


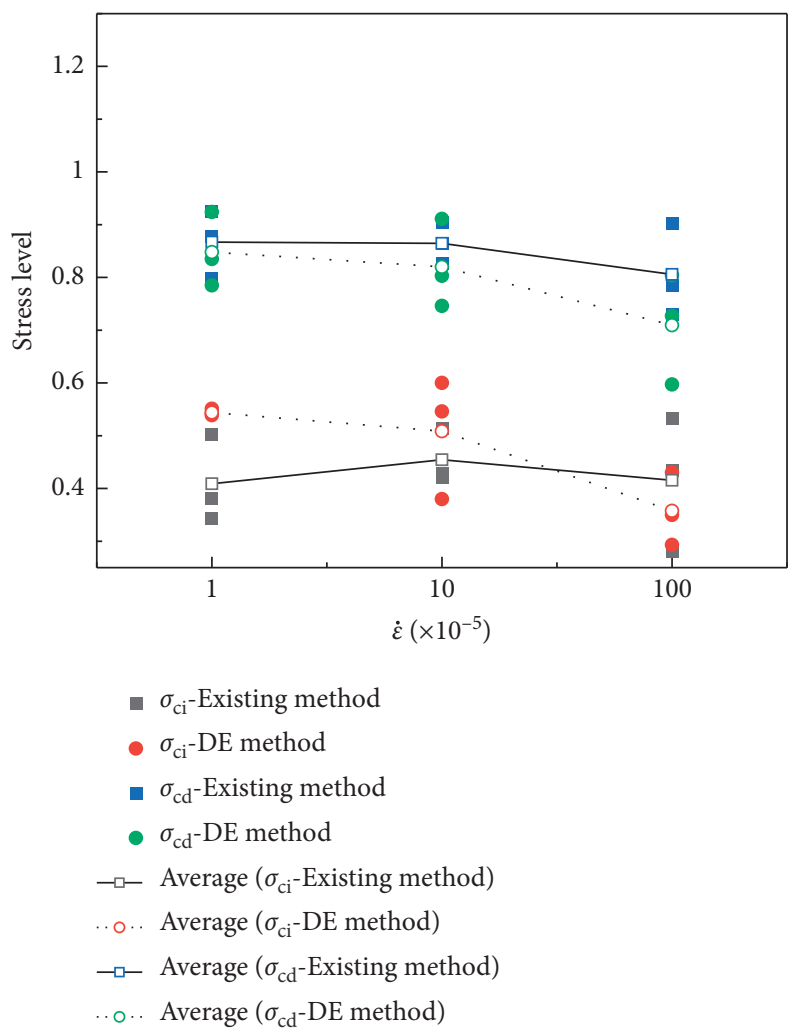

FIgURE 11: Variation of stress threshold determined by two methods at different strain rates.

TABLE 2: Stress thresholds under uniaxial and triaxial conditions.

\begin{tabular}{|c|c|c|c|c|c|c|c|c|}
\hline \multirow{2}{*}{$\begin{array}{l}\text { Confining pressure } \\
\dot{\varepsilon}\end{array}$} & \multicolumn{2}{|c|}{$0 \mathrm{MPa}[43]$} & \multicolumn{2}{|c|}{$25 \mathrm{MPa}$} & \multicolumn{2}{|c|}{$0 \mathrm{MPa}$ [43] } & \multicolumn{2}{|c|}{$25 \mathrm{MPa}$} \\
\hline & $\left(\sigma_{\mathrm{ci}} / \sigma_{f}\right)$ & $\overline{\left(\sigma_{\mathrm{ci}} / \sigma_{f}\right)}$ & $\left(\sigma_{\mathrm{ci}} / \sigma_{f}\right)$ & $\overline{\left(\sigma_{\mathrm{ci}} / \sigma_{f}\right)}$ & $\left(\sigma_{\mathrm{cd}} / \sigma_{f}\right)$ & $\overline{\left(\sigma_{\mathrm{cd}} / \sigma_{f}\right)}$ & $\left(\sigma_{\mathrm{cd}} / \sigma_{f}\right)$ & $\overline{\left(\sigma_{\mathrm{cd}} / \sigma_{f}\right)}$ \\
\hline \multirow{3}{*}{$10^{-5}$} & 0.790 & \multirow{3}{*}{0.627} & 0.542 & & 0.915 & \multirow{3}{*}{0.883} & 0.835 & \multirow{3}{*}{0.848} \\
\hline & 0.550 & & 0.551 & 0.544 & 0.908 & & 0.785 & \\
\hline & 0.541 & & 0.539 & & 0.825 & & 0.924 & \\
\hline \multirow{3}{*}{$10^{-4}$} & 0.495 & \multirow{3}{*}{0.541} & 0.380 & & 0.915 & \multirow{3}{*}{0.850} & 0.746 & \multirow{3}{*}{0.820} \\
\hline & 0.566 & & 0.600 & 0.509 & 0.849 & & 0.911 & \\
\hline & 0.561 & & 0.546 & & 0.787 & & 0.803 & \\
\hline \multirow{3}{*}{$10^{-3}$} & 0.507 & \multirow{3}{*}{0.536} & 0.430 & & 0.813 & \multirow{3}{*}{0.828} & 0.727 & \multirow{3}{*}{0.735} \\
\hline & 0.596 & & 0.293 & 0.358 & 0.863 & & 0.596 & \\
\hline & 0.505 & & 0.350 & & 0.807 & & 0.882 & \\
\hline
\end{tabular}

energy dissipates more, and the corresponding number of cracks is greater.

\section{Conclusions}

Based on AE energy and spatial distribution under $25 \mathrm{MPa}$ confining pressure, the AE parameters and the stress characteristics are analyzed under different strain rates. The AE energy at different strain rates can be divided into four stages: quiet stage, stable growth stage, fast growth stage, and postpeak stage. With the increase of strain rate, AE energy decreases, and the growth rate of AE energy in each stage becomes larger. The spatial distribution of AE under quasistatic strain rate is also characterized by stages. With the increase of strain rate, the spatial distribution of $\mathrm{AE}$ tends to be uniform, and the quantity of $\mathrm{AE}$ decreases and most of $\mathrm{AE}$ occurs in the prepeak stage.

The damage evolution law under quasi-static strain rate is studied, and the damage variable is defined by using the AE energy. The damage evolution curves of coal rock under different strain rates have four stages: initial calm, stable damage evolution, rapid damage evolution, and postpeak stage. With the increase of the strain rate, the rate of change in the stable damage evolution phase increases, and the rate of change in the fast damage evolution phase decreases.

According to the phase characteristics of AE energy, spatial distribution, and damage evolution, determining the 
stress threshold based on damage evolution is proposed. It is determined that the stress level at the beginning of the stable damage evolution stage is the initiation stress, and the stress level at the starting point of the rapid damage evolution stage is the damage stress. Under quasi-static strain rate, $\left(\sigma_{\mathrm{ci}} / \sigma_{f}\right)$ or $\left(\sigma_{\mathrm{cd}} / \sigma_{f}\right)$ determined by the DE method decreases with increasing strain rate. At the same time, the stress thresholds of uniaxial and triaxial under quasi-static strain rate are compared and analyzed. $\overline{\left(\sigma_{\mathrm{ci}} / \sigma_{f}\right)}\left(\right.$ or $\left.\overline{\left(\sigma_{\mathrm{cd}} / \sigma_{f}\right)}\right)$ in the triaxial stress state is always smaller than that in the uniaxial stress state. As the strain rate increases, the difference between uniaxial and triaxial stress states becomes larger.

\section{Data Availability}

The data used to support the findings of this study are included within the article.

\section{Conflicts of Interest}

The authors declare that there are no conflicts of interest regarding the publication of this paper.

\section{Acknowledgments}

The authors acknowledge the Key Laboratory of Deep Earth Science and Engineering, Ministry of Education, Sichuan University, for the experimental support of this research. This research was funded by the key scientific research fund of Sichuan Provincial Department of Education (no. 18ZA0457), the key scientific research fund of Xihua University (no. Z17113), the postgraduate innovation fund of Xihua University (no. YCJJ2019046), and the Opening Fund of Key Laboratory of Deep Earth Science and Engineering, Ministry of Education, Sichuan University (no. DESE202003).

\section{References}

[1] H. P. Xie, "Research review of the state key research development program of China: deep rock mechanics and mining theory," Journal of China Coal Society, vol. 44, no. 5, pp. 1283-1305, 2019.

[2] J. He, L. Dou, S. Gong, J. Li, and Z. Ma, "Rock burst assessment and prediction by dynamic and static stress analysis based on micro-seismic monitoring," International Journal of Rock Mechanics and Mining Sciences, vol. 93, pp. 46-53, 2017.

[3] J. Yu, X. H. Liu, and Q. J. Hao, "Acoustic emission characteristics and damage evolution of coal-rock under different confining pressures," Coal Geology, vol. 48, no. 3, pp. 128-136, 2020.

[4] V. L. Shkuratnik, Y. L. Filimonov, and S. V. Kuchurin, "Experimental investigations into acoustic emission in coal samples under uniaxial loading," Journal of Mining Science, vol. 40, no. 5, pp. 458-464, 2004.

[5] V. L. Shkuratnik, Y. L. Filimonov, and S. V. Kuchurin, "Regularities of acoustic emission in coal samples under triaxial compression," Journal of Mining Science, vol. 41, no. 1, pp. 44-52, 2005.

[6] X. H. Liu, X. P. Zhao, and J. F. Liu, "A study on the acoustic emission characteristics of the coal rock on different bedding direction," Computer Modelling and New Technologies, vol. 18, no. 5, pp. 308-313, 2014.

[7] C. D. Su, B. B. Gao, H. Nan, and X. Li, "Experimental study on acoustic emission characteristics during deformation and failure processes of coal samples under different stress paths," Chinese Journal of Rock Mechanics and Engineering, vol. 28, no. 4, pp. 757-766, 2009.

[8] X. Gao, S. X. Liu, J. W. Huang, and Z. Yang, "The influence of strain rate on $\mathrm{AE}$ characteristics during rock deformation," Chinese Journal of Rock Mechanics and Engineering, vol. 37, no. 4, pp. 887-897, 2018.

[9] H. Li, H. Li, B. Gao, D. Jiang, and J. Feng, "Study of acoustic emission and mechanical characteristics of coal samples under different loading rates," Shock and Vibration, vol. 2015, no. 3, 11 pages, Article ID 458519, 2015.

[10] B. Huang and J. Liu, "The effect of loading rate on the behavior of samples composed of coal and rock," International Journal of Rock Mechanics and Mining Sciences, vol. 61, pp. 23-30, 2013.

[11] N. Wang, Y. Xu, D. Zhu, N. Wang, and B. Yu, "Acoustic emission and failure modes for coal-rock structure under different loading rates," Advances in Civil Engineering, vol. 2018, Article ID 9391780, 11 pages, 2018.

[12] Z. Zhang, R. Zhang, H. Xie, J. Liu, and P. Were, "Differences in the acoustic emission characteristics of rock salt compared with granite and marble during the damage evolution process," Environmental Earth Sciences, vol. 73, no. 11, pp. 6987-6999, 2015.

[13] X. Li and Q. Zhang, "Study on damage evolution and resistivity variation regularities of coal mass under multi-stage loading," Applied Sciences, vol. 9, no. 19, p. 4124, 2019.

[14] A. Cao, G. Jing, Y.-1. Ding, and S. Liu, "Mining-induced static and dynamic loading rate effect on rock damage and acoustic emission characteristic under uniaxial compression," Safety Science, vol. 116, pp. 86-96, 2019.

[15] J.-S. Kim, K.-S. Lee, W.-J. Cho, H.-J. Choi, and G.-C. Cho, “A comparative evaluation of stress-strain and acoustic emission methods for quantitative damage assessments of brittle rock," Rock Mechanics and Rock Engineering, vol. 48, no. 2, pp. $495-508,2014$.

[16] C. D. Martin and N. A. Chandler, "The progressive fracture of Lac du Bonnet granite," International Journal of Rock Mechanics and Mining Sciences \& Geomechanics Abstracts, vol. 31, no. 6, pp. 643-659, 1994.

[17] F. Gong and C. Wu, "Identifying crack compaction and crack damage stress thresholds of rock using load-unload response ratio (LURR) theory," Rock Mechanics and Rock Engineering, vol. 53, no. 2, pp. 943-954, 2020.

[18] F.-Q. Gong, C. Wu, S. Luo, and J.-Y. Yan, "Load-unload response ratio characteristics of rock materials and their application in prediction of rockburst proneness," Bulletin of Engineering Geology and the Environment, vol. 78, no. 7, pp. 5445-5466, 2019.

[19] Z. T. Bieniawski, "Mechanism of brittle fracture of rock: part I-theory of the fracture process," International Journal of Rock Mechanics and Mining Sciences \& Geomechanics Abstracts, vol. 4, no. 4, pp. 395-406, 1967.

[20] Z. T. Bieniawski, "Mechanism of brittle fracture of rock: part II-experimental studies," International Journal of Rock Mechanics and Mining Sciences \& Geomechanics Abstracts, vol. 4, no. 4, pp. 407-423, 1967.

[21] Z. T. Bieniawski, "Mechanism of brittle fracture of rock: part III-fracture in tension and under long-term loading," 
International Journal of Rock Mechanics and Mining Sciences \& Geomechanics Abstracts, vol. 4, no. 4, pp. 425-430, 1967.

[22] M. Cai, P. K. Kaiser, Y. Tasaka, T. Maejima, H. Morioka, and M. Minami, "Generalized crack initiation and crack damage stress thresholds of brittle rock masses near underground excavations," International Journal of Rock Mechanics and Mining Sciences, vol. 41, no. 5, pp. 833-847, 2004.

[23] X. G. Zhao, M. Cai, J. Wang, and L. K. Ma, "Damage stress and acoustic emission characteristics of the Beishan granite," International Journal of Rock Mechanics and Mining Sciences, vol. 64, pp. 258-269, 2013.

[24] R. Kong, X.-T. Feng, X. Zhang, and C. Yang, "Study on crack initiation and damage stress in sandstone under true triaxial compression," International Journal of Rock Mechanics and Mining Sciences, vol. 106, pp. 117-123, 2018.

[25] J. Ning, J. Wang, J. Jiang, S. Hu, L. Jiang, and X. Liu, "Estimation of crack initiation and propagation thresholds of confined brittle coal specimens based on energy dissipation theory," Rock Mechanics and Rock Engineering, vol. 51, no. 1, pp. 119-134, 2018.

[26] M. Nicksiar and C. D. Martin, "Evaluation of methods for determining crack initiation in compression tests on lowporosity rocks," Rock Mechanics and Rock Engineering, vol. 45, no. 4, pp. 607-617, 2012.

[27] E. Eberhardt, D. Stead, and B. Stimpson, "Quantifying progressive pre-peak brittle fracture damage in rock during uniaxial compression," International Journal of Rock Mechanics and Mining Sciences, vol. 36, no. 3, pp. 361-380, 1999.

[28] P. G. Ranjith, D. Jasinge, J. Y. Song, and S. K. Choi, "A study of the effect of displacement rate and moisture content on the mechanical properties of concrete: use of acoustic emission," Mechanics of Materials, vol. 40, no. 6, pp. 453-469, 2008.

[29] H. L. Wang, P. X. Fan, M. Y. Wang, and W. P. Li, "Influence of strain rate on progressive failure process and characteristic stresses of red sandstone," Rock and Soil Mechanics, vol. 32, no. 5, pp. 1340-1346, 2011.

[30] S.-Q. Yang, P. Xu, and P. G. Ranjith, "Damage model of coal under creep and triaxial compression," International Journal of Rock Mechanics and Mining Sciences, vol. 80, pp. 337-345, 2015.

[31] Z. Zhang, H. Xie, R. Zhang et al., "Deformation damage and energy evolution characteristics of coal at different depths," Rock Mechanics and Rock Engineering, vol. 52, no. 5, pp. 1491-1503, 2019.

[32] R. Ulusay, The ISRM Suggested Methods for Rock Characterization, Testing and Monitoring: 2007-2014, Springer, Berlin, Germany, 2014.

[33] D. Krajcinovic and G. U. Fonseka, "The continuous damage theory of brittle materials, part 1: general theory," Journal of Applied Mechanics, vol. 48, no. 4, pp. 809-815, 1981.

[34] G. Xiang, J. Liu, T. Li, and M.-D. Xu-Yang, "Study of fractal and damage characteristic in the deformation and failure process of salt rack based on acoustic emission," Rock and Soil Mechanics, vol. 39, no. 8, pp. 2905-2912, 2018.

[35] X. Xu, B. Liu, S. Li, J. Song, M. Li, and J. Mei, "The electrical resistivity and acoustic emission response law and damage evolution of limestone in Brazilian split test," Advances in Materials Science and Engineering, vol. 2016, Article ID 8052972, 8 pages, 2016.

[36] J. Yang, Y. Zheng, and H. Wang, "Modifications and statistical analysis of acoustic emission models based on the damage and fractal characteristics," Advances in Materials Science and Engineering, vol. 2018, Article ID 1898937, 6 pages, 2018.
[37] B. B. Gao, Experimental Study on Evolution of Cracks and Permeability of Mining Coal, Beijing Jiaotong University, Beijing, China, 2010.

[38] E. Eberhardt, D. Stead, B. Stimpson, and R. S. Read, "Identifying crack initiation and propagation thresholds in brittle rock," Canadian Geotechnical Journal, vol. 35, no. 2, pp. 222-233, 1998.

[39] Y. Wang, X. Li, Y. F. Wu et al., "Research on relationship between crack initiation stress level and brittleness indices for brittle rocks," Chinese Journal of Rock Mechanics and Engineering, vol. 33, no. 2, pp. 264-275, 2014.

[40] M. S. Diederichs, P. K. Kaiser, and E. Eberhardt, "Damage initiation and propagation in hard rock during tunnelling and the influence of near-face stress rotation," International Journal of Rock Mechanics and Mining Sciences, vol. 41, no. 5, pp. 785-812, 2004.

[41] D. F. Cen and D. Huang, "Mesoscopic displacement modes of crack propagation of rock mass under uniaxial compression with high strain rate," Journal of the China Coal Society, vol. 39, no. 3, pp. 436-444, 2014.

[42] P. Fan, M. Wang, and Q. Qian, "Time effect and main influence factors of unloading splitting of deep-seated rock with nonuniformities," Chinese Journal of Rock Mechanics and Engineering, vol. 29, no. 7, pp. 1389-1396, 2010.

[43] X. H. Liu, Q. J. Hao, A. K. Hu et al., "Study on the determination of characteristic stress of uniaxial coal rock under quasi-static strain rate," Chinese Journal of Rock Mechanics and Engineering, vol. 39, 2020 in press. 